\title{
A new structure of a wide band bridge power limiter
}

\author{
Khalifa Echchakhaoui ${ }^{1}$, Elhassane Abdelmounim², Jamal Zbitou ${ }^{3}$, Hamid Bennis ${ }^{4}$ \\ ${ }^{1,2}$ ASTI Laboratory FSTS, Hassan $1^{\text {st }}$ University, Morocco \\ ${ }^{3}$ LMEET Laboratory, FST of Settat, Hassan $1{ }^{\text {st }}$ University, Morocco \\ ${ }^{4}$ Graduate School of Technology of Meknes, Moulay Ismail University, Morocco
}

\begin{tabular}{|c|c|}
\hline Article Info & ABSTRACT \\
\hline Article history: & In this work, new design and simulation of a microstrip power limiter based \\
\hline Received Oct 31, 2019 & $\begin{array}{l}\text { on Schottky diode is presented. The proposed circuit is a zero bias power } \\
\text { limiter built by associating a transmission line in parallel to a four Schottky }\end{array}$ \\
\hline Revised Feb 25, 2020 & rectifier bridge circuit. The first circuit using a single stage rectifier is \\
\hline Accepted Mar 4, 2020 & $\begin{array}{l}\text { analyzed and simulated. To improve this single stage, a second and final } \\
\text { limiter is designed with two stages rectifier. Simulation results for the final }\end{array}$ \\
\hline Keywords: & $\begin{array}{l}\text { circuit show an ideal limiter behavior and good performance of limiting rate } \\
\text { up to } 20 \mathrm{~dB} \text { for a threshold input power varying from } 5 \mathrm{dBm} \text { to } 30 \mathrm{dBm} \text {. }\end{array}$ \\
\hline Microstrip & remains low at sm \\
\hline
\end{tabular}

Microwave power

Power limiter

Schottky diode All rights reserved.

\section{Corresponding Author:}

Khalifa Echchakhaoui,

ASTI Laboratory,

Faculty of Sciences and Techniques,

Hassan $1^{\text {st }}$ University, Settat, Morocco.

Email: k.echakhaoui@gmail.com

\section{INTRODUCTION}

In Microwave systems, Power limiters prevent high incident signal from saturating or damaging sensitive receivers such as rectenna systems and low noise amplifier [1-5] and also allow the receiver to function properly in presence of small signals. The most used limiter technologies are based on solid state components such as PIN diodes [6-8], FET transistors [9-12], and Schottky diodes [13-16]. Other solutions to achieve power limiters are provided by MEMS components [17], vacuum diodes [18] and gas discharge tubes [19].

In this work, commercial HSMS286B Zero-Bias Schottky diode [20] are used to design a low cost microstrip power limiter operating at a frequency of $2.45 \mathrm{GH}$. The proposed power limiter can reduce the amplitude of a large input signal of $30 \mathrm{dBm}$ by 10 to $20 \mathrm{~dB}$. Two types of microwave limiter can be distinguished: active power limiter that requires external current and self-biased limiter operating without DC bias.

The proposed microwave limiter is a self-biased limiter built on two microstrip lines. The first linear line transmits the main signal while the other line is associated to a rectifier bridge constituted of four Schottky diodes. When an incoming signal exceeds Schottky diodes threshold, the rectifier bridge is self-biased causing the drop of diodes impedance and consequently a portion of incoming signal is diverted to ground. The designed circuit has been optimized to provide more than $15 \mathrm{~dB}$ attenuation rate at high signal power while assuring a minimum insertion loss at small signal state.

\section{DESIGN APPROACH}

A simplest solid state limiters consists of one stage diodes or MESFET transistors connecting a line transmission to ground as presented in Figure 1 [21]. In order to take advantage of the variation of its 
impedance as a function of the electric current flowing through it, the diode used to limit the power is placed in anti-parallel form between the transmission line and the common ground. Consequently, when the input power increases, the diode impedance drops down, and some of the received power is diverted to ground. These limiters must present minimal losses for incoming signals under certain threshold power, however beyond this threshold level, losses must be proportional to the incident power [22].

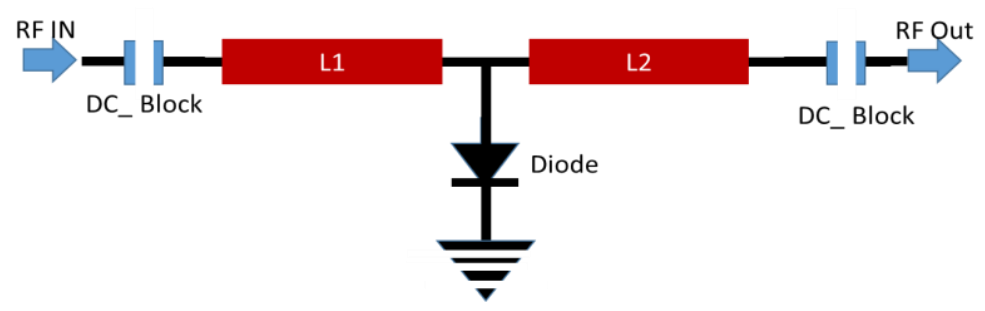

Figure 1. Basic power limiter topology

Such circuit must be equipped with a bias voltage which allows the diode or the MESFET transistors to switch to forward state. The implementation of a bias voltage in microwave system could generate noise and be a source of uncontrolled behavior. However, it is possible to generate the necessary DC biasing current by choosing Zero-Bias diodes $[21,22]$ and using a detector diode as shown in Figure 2. The detector diode will transform a part of incident signal to DC current as used in rectenna systems [23, 24]. On the other hand, the return DC current is ensured by an RF Choke or by the limiter diode itself.

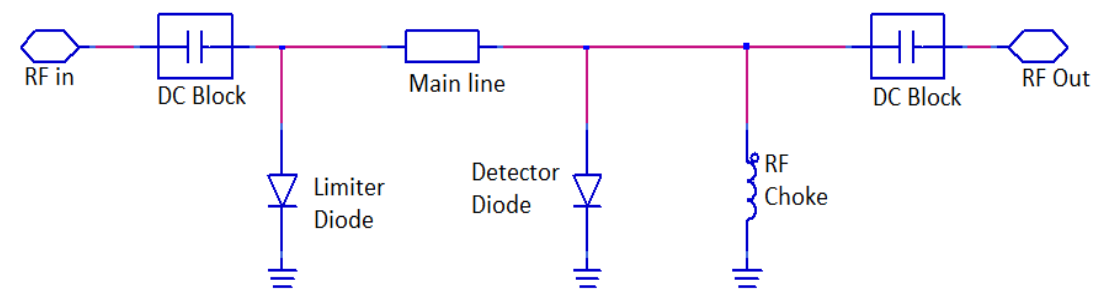

Figure 2. Toplogy of zero bias limiter

In the proposed circuit, we use full wave rectifier bridge circuit topologies optimized for microwave circuit operating at ISM band and using four Schottky diodes. This technique is widely used for rectenna systems and for remote energy harvesting [25, 26] and power detector [27]. As mentioned previously, we chose the Avago HSMS286B commercial diode for validation and design of the proposed circuit. This diode is a surface-mount Schottky RF diode presented in the SOT23/143 package [20].

The HSMS286x family data sheet shows that these diodes are optimized for RF applications from $915 \mathrm{MHz}$ to $5.8 \mathrm{GHz}$. They are used for large signals detection, modulation and rectification of RF signals [20, 24]. Since Advanced Design System (ADS) software is suitable for RF design and natively contains the different HSMS286x families in its library, we used it to validate and simulate the proposed circuit. We validated two circuits in terms of frequency band, insertion loss in small signal mode and attenuation rate when the power received exceeds the threshold limit of the limiter. The circuit is designed by using microstrip technology, based on FR4 substrate with the following parameters:

- Relative dielectric constant: 4.4

- Substrate thickness: $1.6 \mathrm{~mm}$

- Dielectric Loss tangent: 0.025

\section{CIRCUIT OPERATION}

The proposed circuit introduces a new design of a solid state power limiter. The circuit uses a power divider of two lines: The main transmission line in parallel with a second line where we insert a full wave bridge rectifier as depicted in Figure 3. 


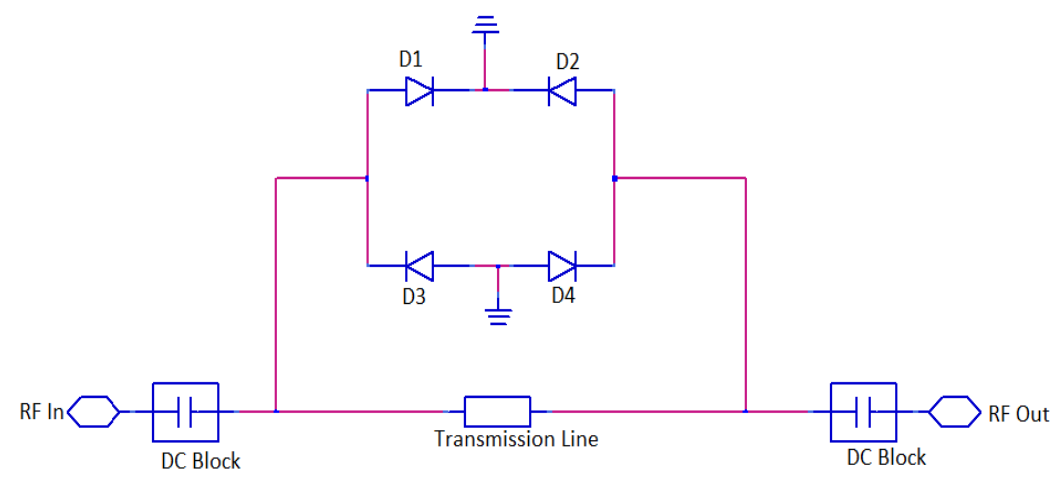

Figure 3. New designed topology

At low power incoming signal, the Schottky diode impedance remains very high because the bridge doesn't activate the rectification. Consequently, the input signal is transmitted to the load with a minimum insertion loss. When the circuit is exposed to a high amplitude signal which exceeds the detection threshold of the Schottky diode, a DC current generated will force the diode impedance to drop down. As a result, part of the incident signal is deflected to the ground.

In order to increase the attenuation level of the circuit, the length of the central line is chosen equal to half wavelength while the diodes are implanted at a distance of half wavelength from the point of derivation. This structure makes a phase shift of $3 \lambda / 2$ between the signal crossing the main transmission line and the signal crossing the rectifier bridge. The microstrip layout of the circuit is illustrated below in Figure 4.

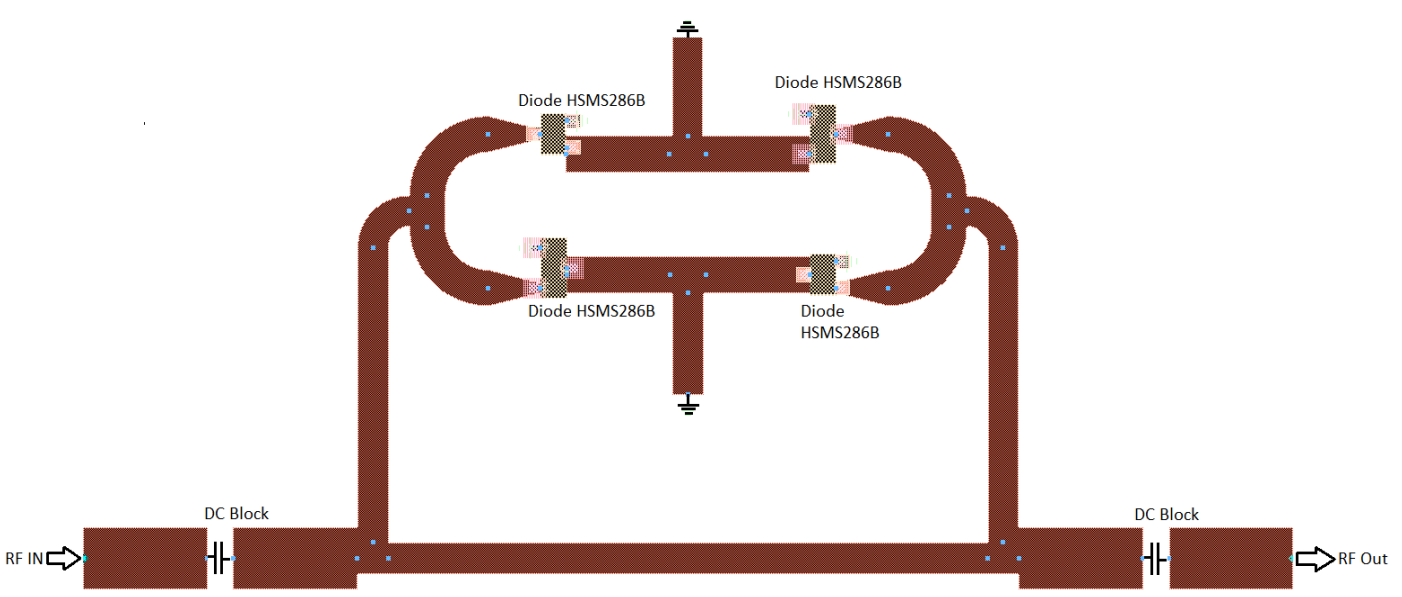

Figure 4. Microstrip structure of the circuit

\subsection{Modelisation of rectifier structures}

Rectifiers are implemented in this limiter circuit to generate DC current required to bias Schottky diode. Generally, RF-DC conversion circuits are based on Schottky diodes. Schottky diodes are selected due to their low junction capacity and low threshold voltage. To analyze the rectifier structure, we consider the equivalent layout of the second line as presented in Figure 5.

Before analyzing this circuit, we need to replace Schottky diodes D1 to D4 by their equivalent lumped circuit. When diodes D1 and D3 receive a positive half cycle Up*sin( $\omega t)$, D2 and D4 will be under negative half cycle $\mathrm{Up}^{*} \sin (\omega \mathrm{t}+\pi)$ because the distance between D1 and D2 is equal to $\lambda / 2$. Since D1 and D2 are in opposite each to other, they will both be in forward bias, while D3 and D4 will be in reverse bias. This above description will be applied for the negative cycle of the signal reaching the diodes D1 and D3. In this situation, diodes D3 and D4 will be the forwarding state and the diodes D1 and D2 will be in the reverse state.

In conclusion, the full wave bridge can be replaced by two diodes at forwarding state and two diodes at reverse state. Hence the bridge in Figure 5 is equivalent to the circuit presented in Figure 6. In Figure 6, 
$\mathrm{Z}_{\mathrm{F}}$ stands for the equivalent impedance of Schottky diode at forwarding state and $\mathrm{Z}_{\mathrm{R}}$ stands for the equivalent impedance of Schottky diode at reverse state. Figure 7 shows a simplified equivalent circuit of a Schottky diode in forward and reverse bias state.

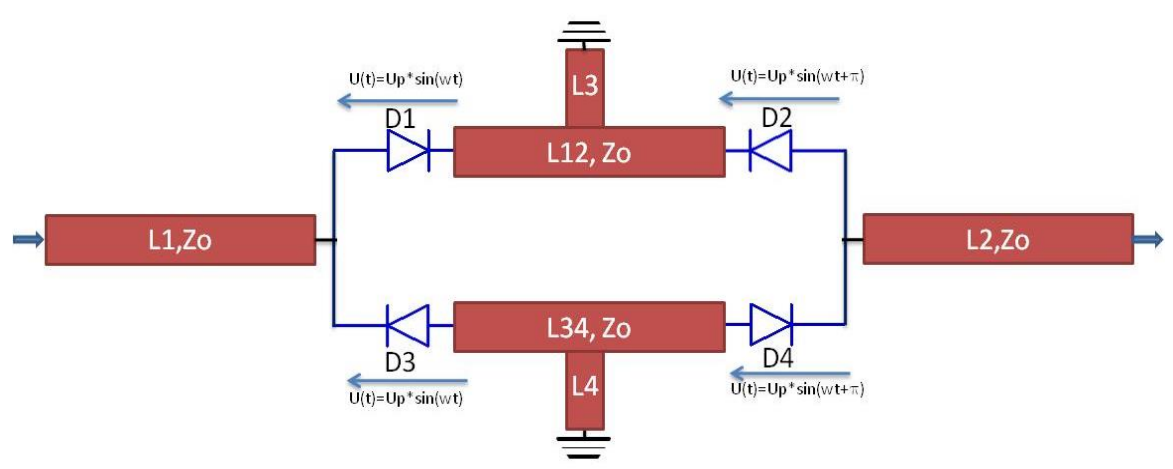

Figure 5. Second line layout

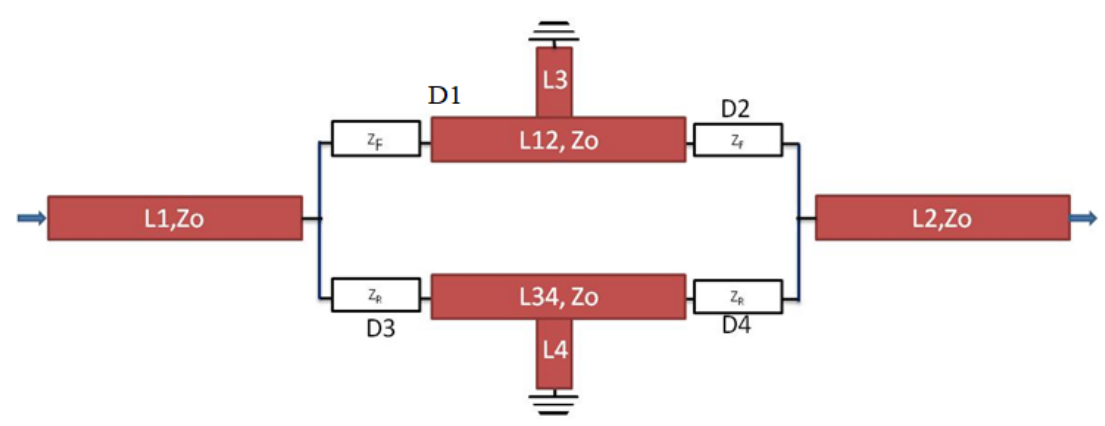

Figure 6. Equivalent circuit of full wave bridge

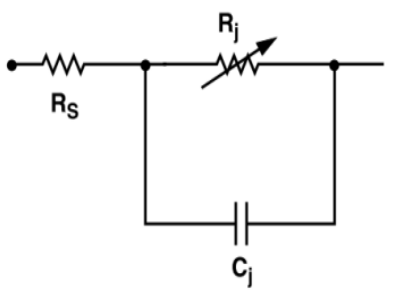

(a)

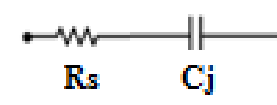

(b)

Figure 7. Simplified equivalent circuit of Schottky diode under (a) forward and (b) reverse bias

Where:

$\mathrm{R}_{\mathrm{s}}$ : series resistance

$\mathrm{R}_{\mathrm{j}}$ : variable resistance as a function of current flowing through the diode

$\mathrm{C}_{\mathrm{j}}$ : the junction capacity

\section{SIMULATION RESULTS}

\subsection{Circuit with one stage}

The circuit presented in Figure 4 has been optimized and validated using ADS software. Figure 8 shows the s-parameters simulation. The output power versus input power is presented in Figure 9 . At an input power of $30 \mathrm{dBm}$, the limiting rate is almost $12 \mathrm{~dB}$. 


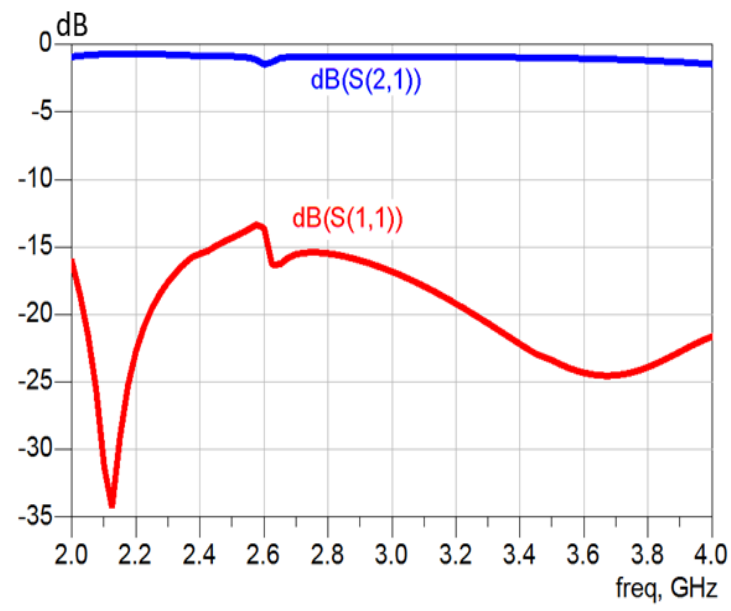

Figure 8. S-parameters simulation

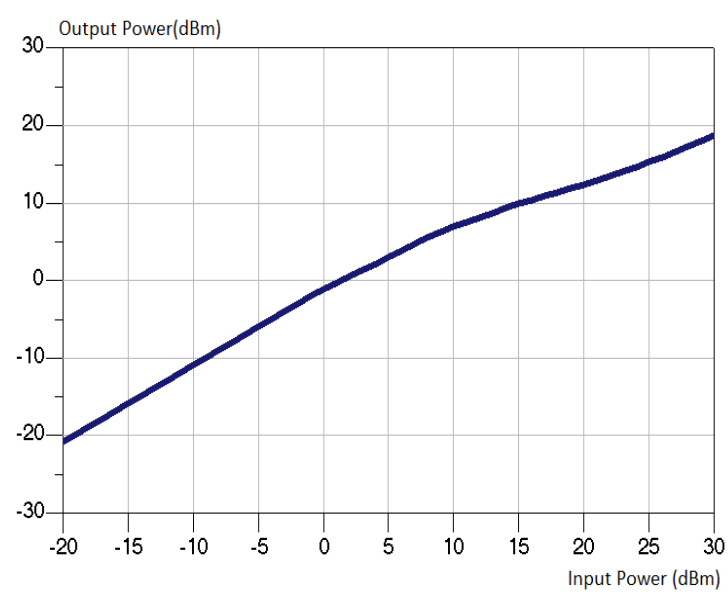

Figure 9. Output power versus Input power at 2.45

S-parameters simulation illustrated in Figure 5 shows that the limiter has good matching input impedance in the ISM band. The insertion loss is established at approximately $0.9 \mathrm{~dB}$ from 2 to $4 \mathrm{GHz}$. However, this structure has certain limitations:

- High limiting power threshold: the device block high power input signal it reaches $10 \mathrm{dBm}$.

- Attenuation obtained at large signal $(12 \mathrm{~dB}$ at Pin=30 dBm) is not sufficient to protect sensitive devices. In order to overcome the above mentioned limitations, we have designed a second circuit consisting of two rectifying bridges.

\subsection{Circuit with two stages}

The improved circuit is formed by two rectifier bridges in parallel with a microstrip transmission line. However, the antidopal lines are replaced by a semicircle in order to reduce circuit dimension. The final circuit is presented in Figure 10. The S-parameters results simulations at small signal and limiting characteristics simulations at high input power are presented in Figure 11.

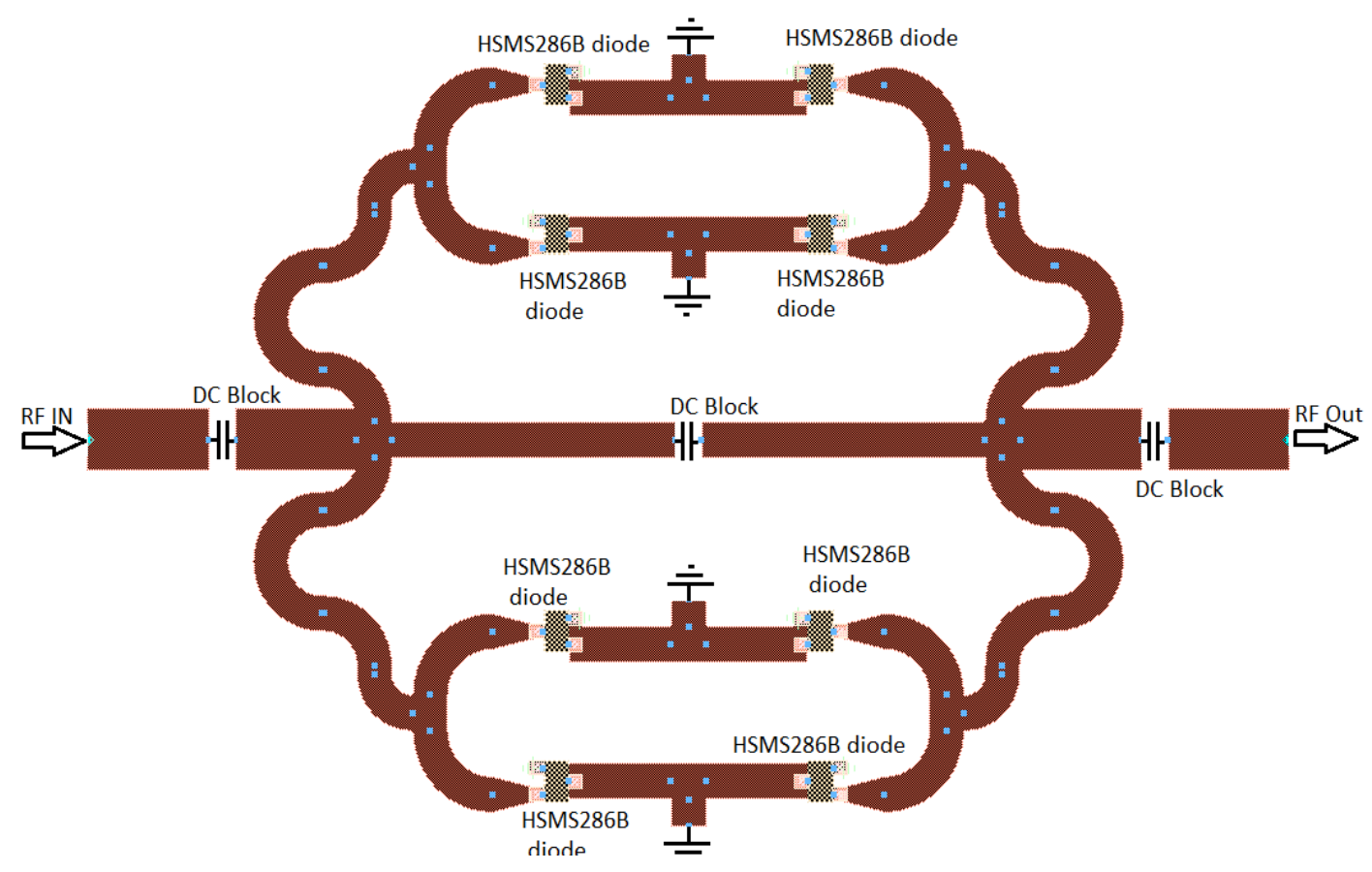

Figure 10. Final circuit with two rectifiers bridges ( 2 stages) 


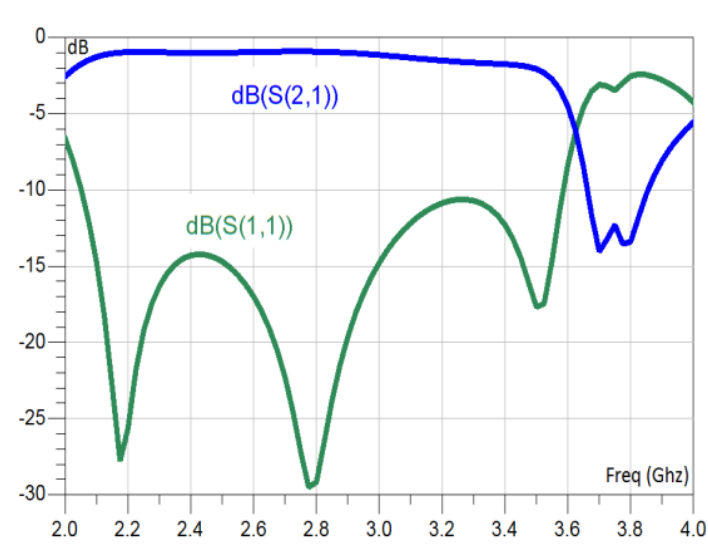

(a)

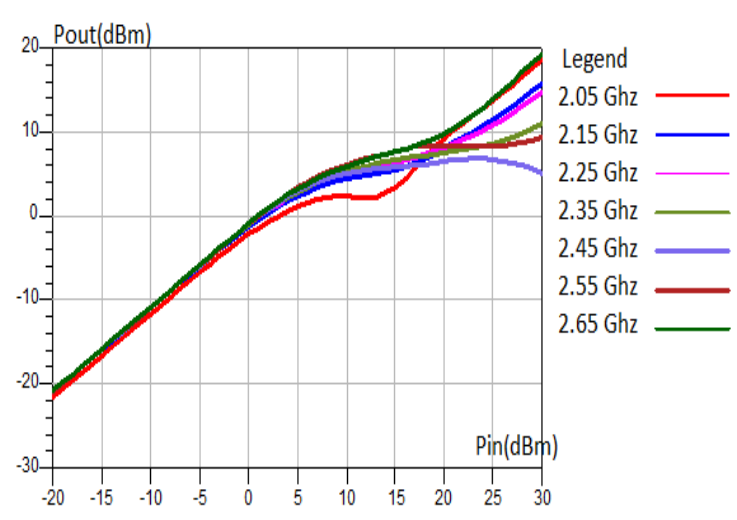

(b)

Figure 11. (a) S-parameters simulation (b) Output Power vs Input Power at [2.05, 2.65] GHz

The two-stage circuit has a better isolation rate compared to the single-stage circuit, while the insertion loss remains in the same level:

- $\quad$ Broadband frequency range of $1 \mathrm{GHz}$ from 2 to $3.6 \mathrm{GHz}$

- $\quad$ Low insertion loss $(-0.9 \mathrm{~dB})$

- $\quad$ The isolation rate reaches $23 \mathrm{~dB}$ at $2.45 \mathrm{GHz}$.

\section{COMPARISON TO SIMILAR LIMITER IN LITERATURE}

Table 1 summarizes a comparison of the proposed circuit with similar limiters reported in scientific literature. It can be seen that the circuit proposed in this paper achieves a small-signal insertion loss below $1 \mathrm{~dB}$ and an attenuation up to $23 \mathrm{~dB}$ over $1.6 \mathrm{GHz}$ frequency band. In terms of power management, the proposed circuit supports $30 \mathrm{dBm}$ exceeding the performance of MMIC circuits. The proposition in [28] presents nearly similar limitation rate, but with a very small bandwidth $(300 \mathrm{MHz})$. While propositions in [29] and Zhou et al., present MMIC limiters with a high reflection rate and low limitation rate compared to the proposed circuit [30].

Table 1. Comparison between the proposed circuit and similar circuits in literature

\begin{tabular}{|c|c|c|c|c|}
\hline & The proposed circuit & Reference [28] & Reference [29] & Reference [30] \\
\hline $\begin{array}{l}\text { Description and devices } \\
\text { used }\end{array}$ & $\begin{array}{l}\text { Planar circuit based } \\
\text { on Schottky diode }\end{array}$ & $\begin{array}{l}\text { Contiguous-Channel } \\
\text { Double Multiplexer } \\
\text { Topology. }\end{array}$ & $\begin{array}{l}180 \mathrm{~nm} \text { SiGeBiCMOS } \\
\text { Technology }\end{array}$ & $\begin{array}{l}\text { Balanced Limiter } \\
\text { associated to Low Noise } \\
\text { Amplifier chip }\end{array}$ \\
\hline Insertion loss & $-0.9 \mathrm{~dB}$ & $-1.8 \mathrm{~dB}$ & $-2 \mathrm{~dB}$ & NA \\
\hline Reflection rate & $-11 \mathrm{~dB}$ & $-15 \mathrm{~dB}$ & $-10 \mathrm{~dB}$ & $-7.8 \mathrm{~dB}$ \\
\hline Limitation rate & $23 \mathrm{~dB}$ & $22 \mathrm{~dB}$ & $13.6 \mathrm{~dB}$ & NA \\
\hline
\end{tabular}

\section{CONCLUSION}

In this work, we have designed and validated by simulation two microstrip microwave power limiter circuits based on Zero-Bias Schottky diodes. At small signal power, the limiter based on one stage rectifier bridge permits a very low insertion loss around $0.9 \mathrm{~dB}$ over $2-4 \mathrm{GHz}$. At High power input, this circuit presents a limitation of $12 \mathrm{~dB}$. To improve the isolation at high signal, a two rectifier bridge stages limiter has been designed and validated. This limiter presents quasi-ideal limiting power characteristic and achieves 23 $\mathrm{dB}$ of isolation rate and a limiting power threshold observed at $0 \mathrm{dBm}$. The dimensions of the layout generated for this circuit are $58.54 \mathrm{~mm} \times 37.05 \mathrm{~mm}$.

\section{ACKNOWLEDGEMENTS}

We have to thank Mr. Angel Mediavilla Professor at the University of Cantabria in Santander, Spain, for his support to this project by giving us the opportunity to use the equipment and software available in his laboratory. 


\section{REFERENCES}

[1] I. J. Bahl, "Control components using Si, GaAs, and GaN technologies," Boston: Artech House, 2014.

[2] A. Agharasouli and M. Tayarani, "Analysis, Design and Implementation of a Waveguide Filter and High Power Limiter," International Journal of Scientific \& Engineering Research, vol. 8, no. 5, pp. 836-838, 2017.

[3] I. J. Bahl, "Ultra broadband 10-W CW integrated limiter," US7724484B2, 2010.

[4] S. C. Bera, et al., "Schottky diode-based microwave limiter with adjustable threshold power level," Microwave and Optical Technology Letters, vol. 52, no. 7, pp. 1671-1673, 2010.

[5] K. Echchakhaoui, E. Abdelmounim, and H. Bennis, "Microwave Power Protectors: Attenuators and Limiters," in Handbook of Research on Advanced Trends in Microwave and Communication Engineering, IGI Global, pp. 244-282, 2017.

[6] L. G. Maloratsky, "Passive RF and Microwave Integrated Circuits," Newnes, 2003.

[7] Chin-Leong Lim, "Recovery time of the Schottky-PIN limiter," Microwave Journal, vol. 55, no. 11, pp. 66-72, 2012.

[8] K. Echchakhaoui, et al., "New Design of Zero Bias Power Limiter Based on Schottky and PIN Diodes," in Proceedings of the 2Nd International Conference on Computing and Wireless Communication Systems, pp. 1-6, 2017.

[9] C. E. Buchinsky and A. Katz, "Passive MESFET Limiters for Wireless Applications," in IEEE Princeton Section Sarnoff Symposium, pp. 0_53-0_56, 1995.

[10] N. V. Drozdovski, "Microwave Passive Power Limiters Based On MESFETs," 1997 SBMO/IEEE MTT-S International Microwave and Optoelectronics Conference, 'Linking to the Next Century', vol. 1, no. 2, pp. 26-36, 1998.

[11] R. J. Gutmann, D. Fryklund, and D. Menzer, "Characterization and Design of GaAs MESFETs for Broadband Control Applications," in 1986 IEEE MTT-S International Microwave Symposium Digest, pp. 389-392, 1986.

[12] C. F. Campbell, J. C. Hitt, and K. Wills, "Wideband GaN FET based limiter MMICs," in 2012 7th European Microwave Integrated Circuit Conference, pp. 417-420, 2012.

[13] K. Echchakhaoui, et al., "A Novel Structure of a Wideband Zero-Bias Power Limiter for ISM Band," TELKOMNIKA (Telecommunication Computing Electronics and Control), vol. 16, no. 6, pp. 2481-2491, 2018.

[14] G. Q. Fan, H. Y. Xing, and H. Q. Hu, "K-Ka band Schottky diode limiter," in Applied Superconductivity and Electromagnetic Devices (ASEMD), IEEE International Conference on, pp. 160-162, 2013.

[15] L. Z. Yang, H. Q. Hu, and J. Xu, "Ka-band schottky diode limiter," in Computational Problem-Solving (ICCP), International Conference on, pp. 639-640, 2011.

[16] A. Y. Yushenko, G. I. Ayzenshtat, and E. A. Monastyryov, "Integral circuits of voltage control limiters," in 2010 IEEE 2nd Russia School and Seminar on Fundamental Problems of Micro/Nanosystems Technologis (MNST), pp. 43-44, 2010.

[17] A. Phommahaxay, et al., "Towards a Fully Passive Ku-Band Power Limiter using RF-MEMS Technologies and Vacuum Microelectronics," in 2006 European Microwave Conference, pp. 1288-1291, 2006.

[18] P. Nicole, A. Phommahaxay, and G. Lissorgues, "Electromagnetic signal power limiter and method of designing the power limiter," US8493160B2, 2013.

[19] Z. V. Missen, A. Semnani, and D. Peroulis, "Toward a High-Power High-Isolation Wideband Plasma Limiter," in 2019 IEEE 20th Wireless and Microwave Technology Conference (WAMICON), pp. 1-4, 2019.

[20] T. Avago, "HSMS-282x, Surface Mount RF Schottky Barrier Diodes," Avago Technologies, 2014.

[21] N. V. Drozdovski, et al., "Microstrip and waveguide passive power limiters with simplified construction," vol. 1, no. 5, pp. 14-29, 1999.

[22] J. Zbitou, M. Latrach, and S. Toutain, "Wide band rectenna with high sensitivity detection," in Proc. Of the 4th Int. conf. on Solar Power from Space-SPS'04, together with the 5th Int. Conf. on Wireless Power transmission- WPT 5, vol. 4, pp. 251-255, 2004.

[23] T Abdellah, et al., "A new design of a microstrip rectenna at $5.8 \mathrm{GHz}$ for wireless power transmission applications," International Journal of Electrical and Computer Engineering (IJECE), vol. 9, no. 2, pp. 1258-1266, 2019.

[24] S. Shawalil, K. N. A. Rani, and H. A. Rahim, "2.45 GHz wearable rectenna array design for microwave energy harvesting," Indonesian Journal of Electrical Engineering and Computer Science (IJEECS), vol. 14, no. 2, pp. 1-4, 2019.

[25] D. H. Chuc and B. G. Duong, "Investigation of Rectifier Circuit Configurations for Microwave Power TransmissionSystem Operating at S Band," International Journal of Electrical and Computer Engineering (IJECE), vol. 5, no. 5, pp. 967-974, 2015.

[26] I. Adam, et al., "Rectifier for RF energy harvesting using stub matching," Indonesian Journal of Electrical Engineering and Computer Science (IJEECS), vol. 13, no. 3, pp. 1007-1013, 2019.

[27] M. M. Ali, et al., "Design and development of RF power detector for microwave application," Indonesian Journal of Electrical Engineering and Computer Science (IJEECS), vol. 13, no. 2, pp. 713-720, 2019.

[28] E. J. Naglich and A. C. Guyette, "Frequency-Selective Limiters Utilizing Contiguous-Channel Double Multiplexer Topology," in IEEE Transactions on Microwave Theory and Techniques, vol. 64, no. 9, pp. 2871-2882, 2016.

[29] V. Budnyaev, I. Filippov, and I. Vetrov, "Microwave Limiter Design in $180 \mathrm{~nm}$ SiGe BiCMOS Technology," in 2019 Ural Symposium on Biomedical Engineering, Radioelectronics and Information Technology (USBEREIT), pp. 398-400, 2019.

[30] X. Zhou, et al., "Design of X-Band Miniature Balanced Limiter-Low Noise Amplifier Chip," in 2018 International Conference on Microwave and Millimeter Wave Technology (ICMMT), pp. 1-3, 2018. 


\section{BIOGRAPHIES OF AUTHORS}
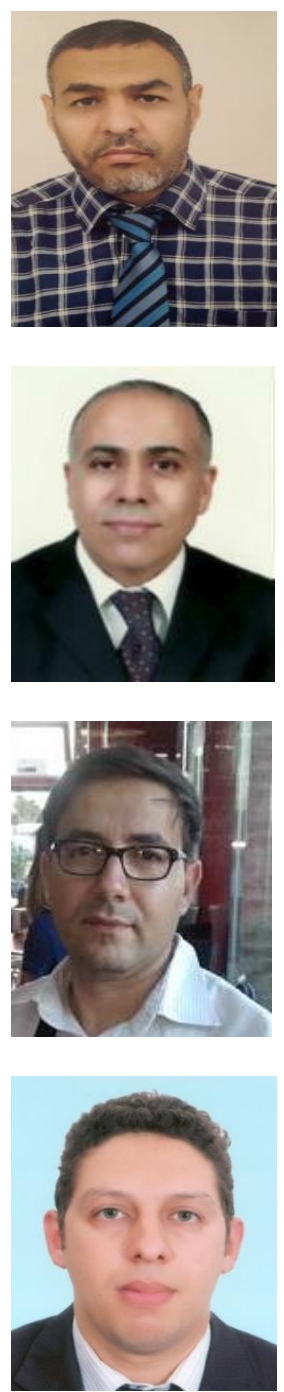

Khalifa Echchakhaoui was born in BenGuérir, Morocco, in 1971. He is a Ph.D. student. His research interests include modeling, design and realization of microwave power control and protector systems.He received the Engineer degree in Computer Science and Telecommunication from the National Post and Telecommunication Institute, Rabat, Morocco, in 1995. He is currently Responsible of Core engineering Department at Morocco Telecom. He is involved in the design and evolution of Mobile Networks Solution and the implementation of 5G technology.

Elhassane Abdelmounim received his $\mathrm{PhD}$ in applied Spectral analysis from Limoges University at science and technical Faculty, France in 1994. In 1996, he joined, as Professor, the applied physics department of the science and technical faculty of Hassan 1st University, Settat, Morocco. His current research interests include digital signal processing and machine learning. He is currently coordinator of a Bachelor of Science in electrical engineering and researcher in "ASTI" System Analysis and Information Technology Laboratory at science and technical faculty, Hassan 1st University, Settat, Morocco.

Jamal Zbitou was born in Fes, Morocco, in June 1976. He received the Ph.D. degree in electronics from Polytech of Nantes, the University of Nantes, Nantes, France, in 2005. He is currently an associate Professor of Electronics in FST, University Hassan 1st, Settat, Morocco and the head of Computing Networks and telecommunication in LMEET Laboratory in FSTS. $\mathrm{He}$ is involved in the design of hybrid, monolithic active and passive microwave electronic circuits.

Hamid Bennis was born in Meknes, Morocco, in September 1977. He received the Ph.D. degree in Computer Science and Telecommunication from the University of Mohammed V Agdal, Rabat, Morocco, in 2011.He is currently a Professor of Computer Science and Computing Network in Graduate School of Technology of Meknes (EST-Meknes), Moulay Ismail University, Meknes, Morocco. He is involved in the design of hybrid, monolithic active and passive microwave electronic circuits. 